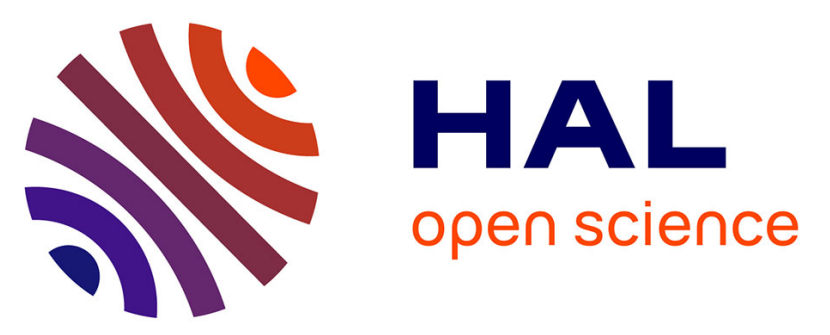

\title{
The effect of spironolactone in patients with obesity at risk for heart failure: proteomic insights from the HOMAGE trial
}

Job a J Verdonschot, João Pedro Ferreira, Anne Pizard, Pierpaolo Pellicori, Hans-Peter Brunner La Rocca, Andrew L Clark, Franco Cosmi, Joe Cuthbert, Nicolas Girerd, Olivia J Waring, et al.

\section{To cite this version:}

Job a J Verdonschot, João Pedro Ferreira, Anne Pizard, Pierpaolo Pellicori, Hans-Peter Brunner La Rocca, et al.. The effect of spironolactone in patients with obesity at risk for heart failure: proteomic insights from the HOMAGE trial. Journal of Cardiac Failure, 2021, S1071-9164 (21), pp.00501-7. 10.1016/j.cardfail.2021.12.005 . hal-03507523

\section{HAL Id: hal-03507523 \\ https://hal.univ-lorraine.fr/hal-03507523}

Submitted on 3 Jan 2022

HAL is a multi-disciplinary open access archive for the deposit and dissemination of scientific research documents, whether they are published or not. The documents may come from teaching and research institutions in France or abroad, or from public or private research centers.
L'archive ouverte pluridisciplinaire $\mathbf{H A L}$, est destinée au dépôt et à la diffusion de documents scientifiques de niveau recherche, publiés ou non, émanant des établissements d'enseignement et de recherche français ou étrangers, des laboratoires publics ou privés.

\section{(ㅇ)(1) $\$$}

Distributed under a Creative Commons Attribution - NonCommercial - NoDerivatives $\mid 4.0$ 


\section{Journal Pre-proof}

The effect of spironolactone in patients with obesity at risk for heart failure: proteomic insights from the HOMAGE trial

Job A.J. Verdonschot MD, PhD , João Pedro Ferreira MD, PhD , Anne Pizard PhD , Pierpaolo Pellicori MD, PhD , Hans-Peter Brunner La Rocca MD, PhD , Andrew L. Clark MD, PhD, Franco Cosmi MD , Joe Cuthbert MD , Nicolas Girerd MD, PhD , Olivia J. Waring MSc , Michiel H.T.M. Henkens MD , Beatrice Mariottoni MD , Johannes Petutschnigg MD , Patrick Rossignol MD, PhD , Mark R. Hazebroek MD, PhD , John G.F. Cleland MD, PhD , Faiez Zannad MD, PhD , Stephane R.B. Heymans MD, PhD , On behalf of HOMAGE "Heart Omics in AGEing" consortium

PII:

DOI: S1071-9164(21)00501-7

Reference: https://doi.org/10.1016/j.cardfail.2021.12.005 YJCAF 4948

To appear in: Journal of Cardiac Failure

Received date:

20 August 2021

Revised date:

Accepted date:

4 December 2021

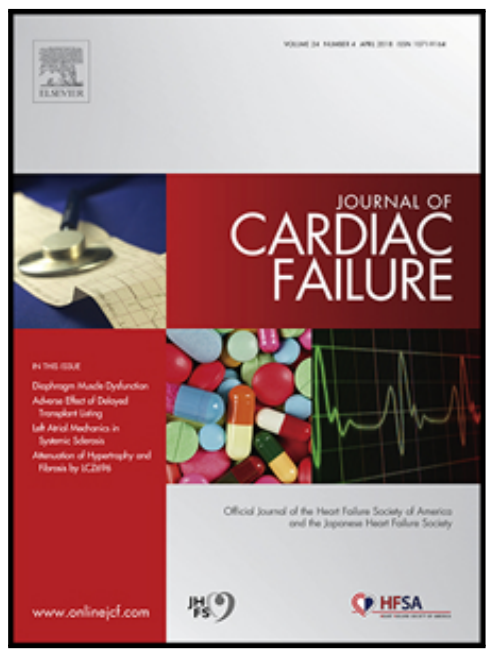

Please cite this article as: Job A.J. Verdonschot MD, PhD, João Pedro Ferreira MD, PhD , Anne Pizard PhD , Pierpaolo Pellicori MD, PhD , Hans-Peter Brunner La Rocca MD, PhD , Andrew L. Clark MD, PhD , Franco Cosmi MD , Joe Cuthbert MD , Nicolas Girerd MD, PhD , Olivia J. Waring MSc, Michiel H.T.M. Henkens MD, Beatrice Mariottoni MD, Johannes Petutschnigg MD , Patrick Rossignol MD, PhD , Mark R. Hazebroek MD, PhD, John G.F. Cleland MD, PhD , Faiez Zannad MD, PhD , Stephane R.B. Heymans MD, PhD , On behalf of HOMAGE "Heart Omics in AGEing" consortium, The effect of spironolactone in patients with obesity at risk for heart failure: proteomic insights from the HOMAGE trial, Journal of Cardiac Failure (2021), doi: https://doi.org/10.1016/j.cardfail.2021.12.005

This is a PDF file of an article that has undergone enhancements after acceptance, such as the addition of a cover page and metadata, and formatting for readability, but it is not yet the definitive version of record. This version will undergo additional copyediting, typesetting and review before it is published in its final form, but we are providing this version to give early visibility of the article. Please note that, during the production process, errors may be discovered which could affect the content, and all legal disclaimers that apply to the journal pertain.

(C) 2021 Published by Elsevier Inc. 


\section{- Research Article -}

\section{The effect of spironolactone in patients with obesity at risk for heart failure: proteomic insights from the HOMAGE trial}

Short title: Proteomics of obesity

Job A.J. Verdonschot, MD, $\mathrm{PhD}^{1}$; João Pedro Ferreira, MD, $\mathrm{PhD}^{2}$; Anne Pizard, $\mathrm{PhD}^{2}$; Pierpaolo Pellicori, MD, PhD ${ }^{3}$; Hans-Peter Brunner La Rocca, MD, $\mathrm{PhD}^{4}$; Andrew L. Clark, MD, PhD ${ }^{5}$; Franco Cosmi, $\mathrm{MD}^{6}$; Joe Cuthbert, $\mathrm{MD}^{5}$; Nicolas Girerd, MD, PhD²; Olivia J. Waring, MSc ${ }^{7}$; Michiel H.T.M. Henkens, $\mathrm{MD}^{4}$; Beatrice Mariottoni, $\mathrm{MD}^{6}$; Johannes Petutschnigg, $\mathrm{MD}^{8}$; Patrick Rossignol, MD, $\mathrm{PhD}^{2}$; Mark. R. Hazebroek, MD, PhD ; John G.F. Cleland, MD, PhD ${ }^{3}$; Faiez Zannad, MD, PhD ${ }^{2}$;Stephane R.B. Heymans, MD, $\mathrm{PhD}^{4}$

On behalf of HOMAGE "Heart Omics in AGEing" consortium

Trial registration number: NCT02556450

\footnotetext{
${ }^{1}$ Department of Clinical Genetics, Maastricht University Medical Center, the Netherlands

${ }^{2}$ Universite de Lorraine, Inserm, Centre d'Investigation Clinique Plurithe'matique 1433, CHRU de Nancy, FCRIN INI-CRCT, Nancy, U1116, France

${ }^{3}$ Robertson Centre for Biostatistics, Institute of Health and Wellbeing, University of Glasgow, Glasgow Royal Infirmary, Glasgow G12 80Q, UK

${ }^{4}$ Department of Cardiology, Maastricht University Medical Center, the Netherlands

${ }^{5}$ Department of Cardiology, University of Hull, Castle Hill Hospital, Cottingham, East Riding of Yorkshire, UK

${ }^{6}$ Department of Cardiology, Cortona Hospital, Arezzo, Italy

${ }^{7}$ Department of Pathology, Maastricht University Medical Center, the Netherlands

${ }^{8}$ Department of Internal Medicine and Cardiology, Campus Virchow Klinikum, Charité University Medicine Berlin, Berlin Institute of Health (BIH), and German Centre for Cardiovascular research (DZHK), Partner Site Berlin, Germany
}

\section{Abstract word count: $199 / 200$ words Total word count: $2684 / 3,500$ words}

Acknowledgments and funding : The research leading to these results has received funding from the European Union Commission's Seventh Framework programme under grant agreement $\mathrm{N}^{\circ}$ 305507 (HOMAGE). S.H.: This manuscript has been possible thanks to the support of the the Netherlands Cardiovascular Research Initiative, an initiative with support of the Dutch Heart Foundation, CVON2016-Early HFPEF, 2015-10, CVON She-PREDICTS, grant 2017-21.

Conflict of interest statement: The authors have no relevant conflicts of interest to disclose with regards to the content of this manuscript.

\section{Address for correspondence:}

Stephane R.B. Heymans

Maastricht University Medical Center (MUMC+)

Department of Cardiology

PO Box 5800

6202 AZ Maastricht

The Netherlands

Ph: $\quad+31433884083$

Fax: $\quad+31433884304$

Email:s.heymans@maastrichtuniversity.nl 


\section{ABSTRACT (199/200 words)}

Background: Adipose tissue influences the expression and degradation of circulating biomarkers. We aimed to identify the biomarker profile and biological meaning of biomarkers associated with obesity, to assess the effect of spironolactone on the circulating biomarkers, and to explore whether obesity might modify the effect of spironolactone.

Methods and results: Protein biomarkers $(n=276)$ from the Olink ${ }^{\circledR}$ Proseek-Multiplex cardiovascular and inflammation panels were measured in plasma collected at baseline, 1 month and 9 months from the HOMAGE randomized controlled trial participants. Of the 510 participants, 299 had obesity defined as an increased waist circumference ( $\geq 102 \mathrm{~cm}$ men and $\geq 88 \mathrm{~cm}$ women). Biomarkers at baseline reflected adipogenesis, increased vascularization, reduced fibrinolysis and glucose intolerance in patients with obesity at baseline. Treatment with spironolactone had only minor effects on this proteomic profile. Obesity modified the effect of spironolactone on systolic blood pressure $\left(p_{\text {interaction }}=0.001\right)$ : showing a stronger decrease of blood pressure in obese patients (14.8mmHg 95\%Cl: -18.45--11.12) compared to non-obese patients $(-3.6 \mathrm{mmHg} 95 \% \mathrm{Cl}-7.82-0.66)$.

Conclusions: Among patients at risk for HF, those with obesity have a characteristic proteomic profile reflecting adipogenesis and glucose intolerance. Spironolactone had only minor effects on this obesity-related proteomic profile, but obesity significantly modified the effect of spironolactone on systolic blood pressure.

Trial registration: NCT02556450

Keywords: obesity; biomarker; heart failure; spironolactone 


\section{BULLET POINTS}

- The proteomic profile of patients with obesity reflects an increased risk for comorbidities such as diabetes and thrombosis.

- Patients with obesity at risk for heart failure might benefit from spironolactone as first line treatment for hypertension.

- Spironolactone provides a similar reduction in fibrosis markers in patients with and without obesity.

\section{LAY SUMMARY (54/100 words)}

Obesity is a well-known risk factor for developing heart failure. Biomarkers measured in the blood show increased adipogenesis and glucose intolerance in patients with obesity. Treatment with spironolactone does not change this biomarker profile. However, patients with obesity have a greater reduction in systolic blood pressure when treated with spironolactone compared to nonobese patients. 


\section{INTRODUCTION}

Obesity is positively associated with incident heart failure (HF) [1]. Body mass index (BMI) is the most commonly used measurement to define obesity but it may not accurately reflect obesity because it does not take fat distribution into account. In this regard, waist circumference (WC) better reflects abdominal fat, which seems to be a stronger risk factor for the development of HF than BMI [2]. Obese patients may have higher aldosterone levels due to hypersecretion of trophic factors from the visceral adipose tissue [3], which may result in mineralocorticoid receptor (MR) over-activation. Obesity might therefore influence the effect of mineralocorticoid receptor antagonist (MRA) therapy. In the EMPHASIS-trial, eplerenone improved outcome in HF patients with and without obesity, although the benefit appeared to be more pronounced among those with abdominal obesity as defined by WC [4].

Adipose tissue influences the expression and degradation of circulating biomarkers [5]. For example, obese patients have lower levels of circulating $\mathrm{N}$-terminal pro brain natriuretic peptide (NT-proBNP). However, little is known regarding the "obesity-related" proteomic profile, especially in those at risk for HF.

The HOMAGE (Heart OMics in AGEing) trial showed that treatment with spironolactone (vs. usual care) in patients at risk of developing HF led to a decrease in collagen synthesis markers, NTproBNP and blood pressure, and improved cardiac remodelling [6]. In this pre-specified analysis of the HOMAGE trial, we aimed 1) to study the biomarker profile and biological meaning of biomarkers associated with obesity, as compared to patients without obesity; 2) to assess the effect of spironolactone on the circulating proteomic biomarkers in patients with obesity; and 3) to explore whether obesity might have modified the effect of spironolactone on the main outcomes assessed in the HOMAGE trial (level of collagen synthesis markers, NT-proBNP systolic and diastolic blood pressure, echocardiographic left atrial volume and left ventricular mass). 


\section{METHODS}

\section{Trial design and population}

The HOMAGE trial had a prospective, randomised, open-label, blinded-endpoint (PROBE), multicentre design. People at increased risk of developing HF were randomly assigned to receive either spironolactone or standard care (ClinicalTrials.gov Identifier: NCT02556450). The rationale, trial design and main results have been published[6,7]. The study was approved by all relevant ethics committees and regulatory bodies. All participants provided written informed consent prior to study-specific procedures. The main participating criteria included age 65 or older (amended to 60 years during the course of the trial), cardiovascular risk defined by either the presence of coronary artery disease $\mathrm{OR}$ at least 2 of the following: diabetes, treated hypertension, microalbuminuria, or an abnormal ECG. Participants also had to have an NT-pro BNP between 125 and 1,000 ng/L or BNP between 35 and $280 \mathrm{ng} / \mathrm{L}$. The main exclusion criteria were glomerular filtration rate (eGFR) <30 $\mathrm{mL} /$ minute $/ 1.73 \mathrm{~m}^{2}$, serum potassium $>5.0 \mathrm{mmol} / \mathrm{L}$, left ventricular ejection fraction $<45 \%$, a diagnosis of HF or treatment with loop diuretics, and atrial fibrillation/flutter. The primary and secondary outcomes measures in the HOMAGE trial were: procollagen type I carboxy-terminal propeptide (PICP)

and procollagen III amino terminal propeptide (PIIINP; both markers of collagen synthesis), NT-pro BNP, systolic and diastolic blood pressure, echocardiographic left atrial volume and left ventricular mass.

For this analysis, patients were divided into two groups based on the presence of obesity as defined by a waist circumference (WC) $\geq 102 \mathrm{~cm}$ for men and $\geq 88 \mathrm{~cm}$ for women[8]. As an additional analysis, obesity was defined based on BMI and all patients were divided into two groups according to the World Health Organization BMI classification (BMI $<30$ and $\geq 30 \mathrm{~kg} / \mathrm{m}^{2}$ ).

\section{Proteomic biomarkers}

Baseline, month 1 and month 9 (or last visit) plasma samples were analysed for 276 protein 
biomarkers by the TATAA-biocenter using the Olink Proseek ${ }^{\circledR}$ Multiplex cardiovascular (CVD) II, CVD III, and inflammation panels. The proteins were determined using high-throughput Olink Proseek ${ }^{\circledR}$ Multiplex 96x96 kits, which measure 92 manually-selected proteins simultaneously in $1 \mu \mathrm{l}$ of plasma per kit. Each kit uses a proximity extension assay (PEA) technology with dual-recognition DNAcoupled readout, where 92 oligonucleotide-labelled antibody probe pairs are allowed to bind to their respective targets in the sample. The platform provides Log2 normalized protein expression (NPX) values with relative quantification. A detailed description of the Olink ${ }^{\circledR}$ technology is depicted in the Supplemental Material.. The abbreviations, full names and respective Olink ${ }^{\circledR}$ multiplex panels of the studied proteins are described in the Supplemental Table 1. The assays were performed blinded to treatment allocation. The proteomic results were then merged into the database.

\section{Statistical analyses}

We compared the characteristics of the patients with and without obesity using the appropriate tests for continuous and categorical variables. To assess whether the baseline biomarkers were expressed differently in patients with and without obesity, we performed logistic regression analyses with obesity as outcome variable and adjusting for age, sex, coronary artery disease, hypertension, and estimated glomerular filtration rate. We corrected the findings for multiple testing using a false discovery rate of $5 \%$. After selecting the proteins with differential expression by obesity, we tested whether spironolactone changed the levels of the proteins. For consistency with the primary report, we used analysis of covariance (ANCOVA) comparing the difference in any changes between the control and spironolactone groups in the regression model[6].

Proteins which were differentially expressed between obese and non-obese patients were used to investigate further. A linear regression model was fitted, with the protein change (from baseline to last visit) as outcome variable, a binary variable to indicate the treatment group (control/spironolactone), and the baseline protein value (NPX) as covariates. The treatment effect was the coefficient that resulted from the comparison of spironolactone vs. control in the regression 
model. Residual analysis was used to examine the fit of the model. No data transformation was required to meet the assumptions of linear regression. Similar analyses were performed for the protein change at 1 month. To study if obesity influences the response to spironolactone on the main outcomes of the study, we performed an ANCOVA analysis with a treatment-by-obesity interaction term. Statistical analyses were performed using Stata ${ }^{\circledR}$ (version 16, StataCorp LP).

\section{Bioinformatical and network analyses}

Only those proteins which were discovered in both $\mathrm{BMI}$ and $\mathrm{WC}$ analyses were used for network analysis and to test for functional enrichment. The aim was to enhance consistency and to limit the likelihood of including incidental proteins based on the definition of obesity. The Search Tool for the Retrieval of Interacting Genes/Proteins (STRING) database was used to analyse functional enrichment (GO biological processes and KEGG pathways) using proteins that were significantly increased or decreased in patients who were obese compared to non-obese at baseline. 


\section{RESULTS}

\section{Clinical characteristics of the study population}

Among the 527 patients included in the HOMAGE trial, 510 were included in the WC analysis (17 patients had a missing WC value). In total, 299 patients (57\%) had a high waist circumference (obese $\mathrm{wc}_{\mathrm{wc}}$ ) (i.e., WC $\geq 102 \mathrm{~cm}$ for men and $\geq 88 \mathrm{~cm}$ for women; Table 1). Compared to patients with normal waist circumference, those with obese ${ }_{w c}$ were more likely to be women, and had more obesity-related comorbidities such as hypertension and diabetes ( $p<0.001$ for both). Regarding the BMI analysis, 525 were included (2 further patients had a missing value). Of these patients, 178 (34\%) had a $\mathrm{BMI} \geq 30 \mathrm{~kg} / \mathrm{m}^{2}$ (obese bmi $_{\text {i }}$. Compared to patients with a $\mathrm{BMI}<30 \mathrm{~kg} / \mathrm{m}^{2}$, those with obese $_{\text {bmi }}$ were younger, but despite their younger age they had more obesity-related comorbidities (Supplemental Table 2). In contrast to obese $\mathrm{wc}_{\mathrm{w}}$, patients with obese $\mathrm{bmi}_{\mathrm{b}}$ did not differ from the nonobese regarding sex. There were no relevant significant differences in baseline characteristic between patients treated with spironolactone or standard care in either the obese $\mathrm{bmi}_{\mathrm{b}}$ or obese $\mathrm{wc}_{\mathrm{wc}}$ subgroups (Supplemental Table 3 and 4).

\section{Proteomic profile at baseline}

At baseline, patients with obese ${ }_{w c}$ had greater expression of 19 proteins and lower expression of 3 proteins compared to non-obese ${ }_{w c}$ patients (Table 2). Twelve of these proteins (9 increased, 3 decreased) were also found in obese ${ }_{b m i}$ patients, suggesting that of those proteins tested, these 12 are the most robustly associated with obesity irrespective of definition (Supplemental Table 5).

The 12 proteins strongly clustered in biological processes related to: [1] lipid metabolism, [2] angiogenesis, and [3] insulin signalling (Figure 1). Adrenomedullin (ADM) showed the strongest positive correlation with obesity ( $\beta$-coefficient 9.03 [6.35 - 11.7], Table 2 ) and is involved in all processes, as is also the case for leptin (LEP). The proteomic profile of the obese patient reflects increased adipogenesis, increased vascularization, reduced fibrinolysis and greater glucose intolerance (Figure 2). 


\section{Proteomic changes with spironolactone in obese patients}

Among the differentially expressed proteins in obese patients (Table 2), spironolactone induced a mild but significant increase in leptin (LEP) and fatty acid-binding protein 4 (FABP4) at 1 month, a mild increase of FABP4, chemerin (RARRES2), perlecan (PLC) and adrenomedullin (ADM) at 9 months, and a mild decrease of thrombospondin-2 (THBS2) at 9 months (Supplemental Table 6).

\section{Interaction of obesity with the main trial outcomes}

The modifying effect of obesity on the impact of spironolactone for each of the main HOMAGE trial outcomes [6] is shown in Table 3. The interaction between spironolactone and obese ${ }_{w c}$ reached statistical significance only for systolic blood pressure $\left(p_{\text {int }}=0.001\right)$, meaning that obese $e_{w c}$ patients had a significant greater decrease of systolic blood pressure $(-14.8 \mathrm{mmHg})$ in response to spironolactone compared to non-obese $\mathrm{wc}_{\mathrm{c}}$ patients $(-3.6 \mathrm{mmHg})$. There was also a trend indicating a greater decrease in diastolic blood pressure in obese ${ }_{w c}$ patients $\left(p_{\text {int }}=0.06\right)$. 


\section{DISCUSSION}

Investigating the clinical and proteomic response to spironolactone in patients with obesity showed that: (i) obese individuals have a plasma proteomic profile reflecting adipogenesis, increased vascularization, reduced fibrinolysis and glucose intolerance; (ii) spironolactone has only a minor influence on this proteomic profile, but (iii) obesity modifies the antihypertensive effect of spironolactone. Obesity might therefore modify the effects of spironolactone in patients with elevated cardiovascular risk.

\section{Spironolactone treatment in patients with obesity}

We observed a significant interaction between obesity and reduction in systolic blood pressure: patients with obesity had a stronger anti-hypertensive response to spironolactone compared to nonobese patients. Obesity is characterized by high circulating levels of aldosterone, which can be directly secreted by adipocytes or may be released from the adrenal gland in response to leptin [9]. The increased levels of leptin in obese patients may be responsible for the excessive mineralocorticoid receptor signalling that is the hallmark of obesity-related HF [4]. Rat studies showed that interference with the mineralocorticoid receptor signalling by using antagonists (MRAs) delayed HF onset in both lean and obese rats, but the obese rats showed an additional improvement regarding to cardiac fibrosis, obesity and dyslipidaemia [10]. Also in mice, MRA treatment attenuated the obesity-related insulin resistance through reduction of inflammation and oxidative stress [11]. In the EMPHASIS-HF trial, eplerenone improved outcome in HFrEF patients, with the most benefit in those with abdominal obesity [4]. The same observation was made in the TOPCAT trial which investigated spironolactone treatment in patients with HFpEF: the favourable effect of MRA was most apparent in obese patients who had elevated levels of aldosterone [12]. Treatment with a MRA can thus be considered as a first line agent for hypertension in obese patients at risk for HF. 
In our study, we analysed the influence of spironolactone on the proteomic profile of obese patients at risk for HF. Spironolactone had only a minor influence on the proteomic profile of obese patients, only leptin, FABP4, RARRES2, THBS2, ADM and PLC were minimally altered after 1 and 9 months of treatment. The increase in leptin could be a positive feedback-loop as a result of interfering in the leptin-aldosterone-neprilysin axis [9]. The other proteomic markers in the circulation are mostly secreted by the adipose tissue or as a response to increased fatty acids in the circulation. Although spironolactone has pleiotropic effects, it does not influence the substrate metabolism which partly explains the minor influence of spironolactone on the proteomic profile [13].

Obesity did modify the anti-hypertensive effect of spironolactone, showing that obese patients at risk for heart failure have greater benefit from spironolactone compared to those who are not overweight. Although aldosterone was not measured in the HOMAGE trial, a relative hyperaldosteronism in obese patients may explain the beneficial effect of spironolactone on blood pressure [14]. However, even if the effects of spironolactone on blood pressure are greater in those with obesity, spironolactone still improved cardiac remodelling in those without obesity suggesting additional beneficial mechanisms in people at risk beyond blood pressure reduction [13].

\section{Biological proteome profile of patients with obesity}

The most commonly used measurement to define obesity is BMI, although this does not take fat distribution into account. Abdominal fat is a potential risk factor in the onset of $\mathrm{HF}$, and is better reflected by measuring the WC [2]. We used both $\mathrm{BMI}$ and WC to find the most consequent proteins associated with obesity in order to minimize incidental findings. Twelve biomarkers were strongly associated with obesity, of which nine circulating proteins were elevated and three were decreased in obese people. Collectively these biomarkers reflect a metabolic profile of insulin resistance, (adipose) angiogenesis, expansion of adipocytes, thrombosis and a dysregulated substrate metabolism, which is summarized step by step in Figure 2 . 
The biological function of these twelve proteins can be directly associated to obesity, and most of the described proteins can be directly or indirectly linked to HF or cardiac disease. The increase in adipose tissue is associated with an elevated serum concentration of the adipokines adrenomedullin (ADM), leptin (LEP), fatty acid-binding protein 4 (FABP4) and chemerin (RARRES2) (1) [15-18]. By autocrine signalling, leptin can influence the metabolism of adipocytes directly (via the leptin receptors on adipocytes) and indirectly, as it modifies the insulin sensitivity of adipocytes in order to stimulate oxidative substrate metabolism and to inhibit lipid accumulation [18]. In addition, increased leptin signalling can promote cardiac inflammation, microcirculatory abnormalities and cardiac fibrosis [9]. Chemerin also works in an autocrine loop to induce differentiation and expansion of pre-adipocytes towards adipocytes [17]. Leptin, adrenomedullin and chemerin all stimulate angiogenesis, thereby ensuring sufficient blood supply for the adipocyte expansion (2) [19-21]. Thrombospondin-2 (THBS2) is a well-known modulator of extracellular matrix remodelling during angiogenesis [22]. Adrenomedullin improves the integrity of the blood vessels, and thereby reduces the vascular permeability. In addition, it causes dilation of the blood vessels by exerting its effect on the vascular smooth muscle cells $(3)[23,24]$. Fatty acid-binding protein 4 acts as a chaperone for long-chain fatty acids (FA) in the circulation, and transports these to the organs $(4)[15,25]$. Oxidative stress associated with increasing visceral fat leads to a conformational change of FABP4, which prevents the protein to bind FAs effectively. This eventually leads to a dysregulation of communication between energy-storage systems and organs, disrupting glucose homeostasis and mediating insulin resistance. Plasminogen activator (PAI)-1, expressed by the SERPINE1 gene, is mainly secreted from the liver and the adipose tissue and blocks the activation of fibrinolysis, thereby limiting the dissolution of the fibrin clot $(5)[26,27]$. Obesity is associated with a marked increase of plasma PAI-1 levels, mainly because PAI-1 is implicated in adipose tissue development and insulin signalling in adipocytes. The impaired fibrinolysis, together with endothelial dysfunction, hyper-reactivity of platelets and hypercoagulability contribute to a pro-thrombotic state in patients with obesity [26]. 
Paraoxonase-3 concentration is decreased in patients with obesity. This protein is secreted by the liver and is anchored to high-density lipoprotein (HDL) particles in the circulation, and prevent low-density lipoprotein (LPL) particles from oxidation (6) [28]. Low levels of circulating PON3 are a risk factor for atherosclerosis and obesity due to disturbed lipid metabolism [29]. Levels of insulinlike growth factor-binding protein 1 and 2 (IGFBP1 and IGFBP2) are strongly associated with insulin sensitivity: thus the low levels of IGFBP-1 and 2 reflect insulin resistance [30]. The IGFBPs prevent adipocyte differentiation and adipogenesis. Levels of interleukin-1 receptor antagonist (IL1RN) are associated with measures of obesity and insulin resistance (7) [31]. The increased levels of inflammatory cytokines compete with insulin for binding of the insulin receptor. As a consequence the substrate metabolism is disturbed, leading to decreased fat to carbohydrate oxidation rate [32].

\section{Limitations}

We tested the effect of spironolactone on multiple proteins applying a correction for test multiplicity to limit the occurrence of false positive findings; however, as HOMAGE was a randomized controlled trial, other proteins, whose levels were also significantly changed with spironolactone, might also be implicated in relevant pathways and biological processes and might be worth exploring in further studies. Additionally, many of the highlighted mechanisms should be furtherly replicated and confirmed at a cellular level. The effect of spironolactone (versus standard of care) on the circulating proteins associated with obesity was tested as an exploratory analysis and not corrected for multiplicity of tests. Such results require further replication and should be interpreted with caution. About $68 \%$ of the included subjects in the HOMAGE trial had $>250$ days of follow-up, meaning that a minority of patients did not have 9 months of follow-up. However, in the HOMAGE clinical trial we observed that most of the effects of spironolactone on biomarkers occurred after 1 month of treatment [6].

\section{CONCLUSION}


Among patients at risk for $\mathrm{HF}$, those with obesity have a characteristic proteomic profile reflecting adipogenesis and glucose intolerance. Spironolactone had only a minor effect on this 'obesityrelated' proteomic profile, but obesity modified the effect of spironolactone on systolic blood pressure.

\section{REFERENCES}

[1] Bui AL, Horwich TB, Fonarow GC. Epidemiology and risk profile of heart failure. Nature reviews Cardiology. 2011;8:30-41. 10.1038/nrcardio.2010.165

[2] Aune D, Sen A, Norat T, Janszky I, Romundstad P, Tonstad S, et al. Body Mass Index, Abdominal Fatness, and Heart Failure Incidence and Mortality: A Systematic Review and Dose-Response MetaAnalysis of Prospective Studies. Circulation. 2016;133:639-49. 10.1161/circulationaha.115.016801

[3] Mathieu P, Boulanger MC, Després JP. Ectopic visceral fat: a clinical and molecular perspective on the cardiometabolic risk. Reviews in endocrine \& metabolic disorders. 2014;15:289-98. 10.1007/s11154-014-9299-3

[4] Olivier A, Pitt B, Girerd N, Lamiral Z, Machu JL, McMurray JJV, et al. Effect of eplerenone in patients with heart failure and reduced ejection fraction: potential effect modification by abdominal obesity. Insight from the EMPHASIS-HF trial. European journal of heart failure. 2017;19:1186-97. 10.1002/ejhf.792

[5] Streng KW, Ter Maaten JM, Cleland JG, O'Connor CM, Davison BA, Metra M, et al. Associations of Body Mass Index With Laboratory and Biomarkers in Patients With Acute Heart Failure. Circ Heart Fail. 2017;10. 10.1161/circheartfailure.116.003350

[6] Cleland JGF, Ferreira JP, Mariottoni B, Pellicori P, Cuthbert J, Verdonschot JAJ, et al. The effect of spironolactone on cardiovascular function and markers of fibrosis in people at increased risk of developing heart failure: the heart 'OMics' in AGEing (HOMAGE) randomized clinical trial. European Heart Journal. 2020. 10.1093/eurheartj/ehaa758

[7] Pellicori P, Ferreira JP, Mariottoni B, Brunner-La Rocca HP, Ahmed FZ, Verdonschot J, et al. Effects of spironolactone on serum markers of fibrosis in people at high risk of developing heart failure: rationale, design and baseline characteristics of a proof-of-concept, randomised, precision-medicine, prevention trial. The Heart OMics in AGing (HOMAGE) trial. European journal of heart failure. 2020;22:1711-23. 10.1002/ejhf.1716

[8] Jensen MD, Ryan DH, Apovian CM, Ard JD, Comuzzie AG, Donato KA, et al. 2013 AHA/ACC/TOS guideline for the management of overweight and obesity in adults: a report of the American College of Cardiology/American Heart Association Task Force on Practice Guidelines and The Obesity Society. Circulation. 2014;129:S102-38. 10.1161/01.cir.0000437739.71477.ee

[9] Packer M. Leptin-Aldosterone-Neprilysin Axis: Identification of Its Distinctive Role in the Pathogenesis of the Three Phenotypes of Heart Failure in People With Obesity. Circulation. 2018;137:1614-31. 10.1161/circulationaha.117.032474

[10] Youcef G, Olivier A, Nicot N, Muller A, Deng C, Labat C, et al. Preventive and chronic mineralocorticoid receptor antagonism is highly beneficial in obese SHHF rats. British journal of pharmacology. 2016;173:1805-19. 10.1111/bph.13479

[11] Hirata A, Maeda N, Hiuge A, Hibuse T, Fujita K, Okada T, et al. Blockade of mineralocorticoid receptor reverses adipocyte dysfunction and insulin resistance in obese mice. Cardiovascular research. 2009;84:164-72. 10.1093/cvr/cvp191

[12] Anand IS, Claggett B, Liu J, Shah AM, Rector TS, Shah SJ, et al. Interaction Between Spironolactone and Natriuretic Peptides in Patients With Heart Failure and Preserved 
Ejection Fraction: From the TOPCAT Trial. JACC Heart failure. 2017;5:241-52. 10.1016/j.jchf.2016.11.015

[13] Ferreira JP, Verdonschot J, Wang P, Pizard A, Collier T, Ahmed FZ, et al. Proteomic and Mechanistic Analysis of Spironolactone in Patients at Risk for HF. JACC Heart failure. 2021;9:268-77. 10.1016/j.jchf.2020.11.010

[14] Bomback AS, Muskala P, Bald E, Chwatko G, Nowicki M. Low-dose spironolactone, added to long-term ACE inhibitor therapy, reduces blood pressure and urinary albumin excretion in obese patients with hypertensive target organ damage. Clinical nephrology. 2009;72:449-56. $10.5414 /$ cnp72449

[15] Furuhashi M. Fatty Acid-Binding Protein 4 in Cardiovascular and Metabolic Diseases. Journal of atherosclerosis and thrombosis. 2019;26:216-32. 10.5551/jat.48710

[16] Li Y, Jiang C, Wang X, Zhang Y, Shibahara S, Takahashi K. Adrenomedullin is a novel adipokine: adrenomedullin in adipocytes and adipose tissues. Peptides. 2007;28:1129-43. 10.1016/j.peptides.2007.03.005

[17] Helfer G, Wu QF. Chemerin: a multifaceted adipokine involved in metabolic disorders. The Journal of endocrinology. 2018;238:R79-r94. 10.1530/joe-18-0174

[18] Harris RB. Direct and indirect effects of leptin on adipocyte metabolism. Biochimica et biophysica acta. 2014;1842:414-23. 10.1016/j.bbadis.2013.05.009

[19] Ribatti D, Nico B, Spinazzi R, Vacca A, Nussdorfer GG. The role of adrenomedullin in angiogenesis. Peptides. 2005;26:1670-5. 10.1016/j.peptides.2005.02.017

[20] Buechler C, Feder S, Haberl EM, Aslanidis C. Chemerin Isoforms and Activity in Obesity. International journal of molecular sciences. 2019;20. 10.3390/ijms20051128

[21] Tahergorabi Z, Khazaei M. Leptin and its cardiovascular effects: Focus on angiogenesis. Advanced biomedical research. 2015;4:79. 10.4103/2277-9175.156526

[22] Krady MM, Zeng J, Yu J, MacLauchlan S, Skokos EA, Tian W, et al. Thrombospondin-2 modulates extracellular matrix remodeling during physiological angiogenesis. The American journal of pathology. 2008;173:879-91. 10.2353/ajpath.2008.080128

[23] Kitamura K, Kangawa K, Kawamoto M, Ichiki Y, Nakamura S, Matsuo H, et al. Adrenomedullin: a novel hypotensive peptide isolated from human pheochromocytoma. Biochemical and biophysical research communications. 1993;192:553-60. 10.1006/bbrc.1993.1451

[24] Voors AA, Kremer D, Geven C, Ter Maaten JM, Struck J, Bergmann A, et al. Adrenomedullin in heart failure: pathophysiology and therapeutic application. European journal of heart failure. 2019;21:163-71. 10.1002/ejhf.1366

[25] Prentice KJ, Saksi J, Hotamisligil GS. Adipokine FABP4 integrates energy stores and counterregulatory metabolic responses. Journal of lipid research. 2019;60:734-40. 10.1194/jIr.S091793

[26] Vilahur G, Ben-Aicha S, Badimon L. New insights into the role of adipose tissue in thrombosis. Cardiovascular research. 2017;113:1046-54. 10.1093/cvr/cvx086

[27] Zheng Z, Nakamura K, Gershbaum S, Wang X, Thomas S, Bessler M, et al. Interacting hepatic PAI$1 /$ tPA gene regulatory pathways influence impaired fibrinolysis severity in obesity. The Journal of clinical investigation. 2020;130:4348-59. 10.1172/jci135919

[28] Ribas V, Sánchez-Quesada JL, Antón R, Camacho M, Julve J, Escolà-Gil JC, et al. Human apolipoprotein A-II enrichment displaces paraoxonase from HDL and impairs its antioxidant properties: a new mechanism linking HDL protein composition and antiatherogenic potential. Circulation research. 2004;95:789-97. 10.1161/01.RES.0000146031.94850.5f

[29] Shih DM, Xia YR, Wang XP, Wang SS, Bourquard N, Fogelman AM, et al. Decreased obesity and atherosclerosis in human paraoxonase 3 transgenic mice. Circulation research. 2007;100:1200-7. 10.1161/01.Res.0000264499.48737.69

[30] Haywood NJ, Slater TA, Matthews CJ, Wheatcroft SB. The insulin like growth factor and binding protein family: Novel therapeutic targets in obesity \& diabetes. Molecular metabolism. 2019;19:8696. 10.1016/j.molmet.2018.10.008 
[31] Charles BA, Doumatey A, Huang H, Zhou J, Chen G, Shriner D, et al. The roles of IL-6, IL-10, and IL-1RA in obesity and insulin resistance in African-Americans. The Journal of clinical endocrinology and metabolism. 2011;96:E2018-22. 10.1210/jc.2011-1497

[32] Chida D, Hashimoto O, Kuwahara $M$, Sagara $H$, Osaka $T$, Tsubone $H$, et al. Increased fat:carbohydrate oxidation ratio in $\| 1 \mathrm{ra} \mathrm{(-/-)} \mathrm{mice} \mathrm{on} \mathrm{a} \mathrm{high-fat} \mathrm{diet} \mathrm{is} \mathrm{associated} \mathrm{with} \mathrm{increased}$ sympathetic tone. Diabetologia. 2008;51:1698-706. 10.1007/s00125-008-1075-z 


\section{FIGURE LEGENDS}

FIGURE 1. Network of protein biomarkers which were significantly differentially detected in patients with obesity compared to non-obese patients $(F D R q<0.05)$. The full names of the proteins are depicted in Supplemental Table 1. The Search Tool for the Retrieval of Interacting Genes/Proteins (STRING) database was used to analyse functional enrichment (GO biological processes and KEGG pathways) using these proteins. Four major pathways could be retrieved from this analysis as reflected by corresponding colours (left). Meta-clustering revealed involvement of proteins in single, or in multiple biological processes (right). P3NP was not depicted in the figure as it is a product of collagen production which could not be analysed for protein-protein interactions.

FIGURE 2. Summary of the biological processes of the biomarkers which are differentially expressed in obese patient compared to non-obese patients. (1) the adipokines leptin (LEP), adrenomedullin (ADM), fatty acid-binding protein 4 (FABP4) and chemerin (RARRES2) are secreted from the adipocytes into the circulation. Leptin and chemerin work in an autocrine feedback loop to stimulate oxidative substrate metabolism. (2) Leptin, adrenomedullin and chemerin all stimulate angiogenesis, thrombospondin-2 (THBS2) is a well-known modulator of extracellular matrix remodelling during angiogenesis. (3) Adrenomedullin causes dilation of the blood vessels by exerting its effect on the vascular smooth muscle cells. (4) Fatty acid-binding protein 4 acts as a chaperone for long-chain fatty acids (FA) in the circulation, and transports these to the organs. (5) Plasminogen activator (PAI)1 blocks the activation of fibrinolysis, thereby limiting the dissolution of the fibrin clot. (6) Paraoxonase-3 (PON3) is anchored to high-density lipoprotein (HDL) particles in the circulation, and prevent low-density lipoprotein (LPL) particles from oxidation. (7) Insulin-like growth factor-binding protein-1 and 2 (IGFBP-1 and IGFBP-2) are strongly associated with insulin sensitivity and prevent adipocyte differentiation and adipogenesis.

The proteins in the red squares (IGFBP-1, IGFBP-2 and PON3) are decreased in obese patients. P3NP was not depicted in the figure as it is a product of collagen production which could not be analysed for protein-protein interactions. Figure created with BioRender.com 


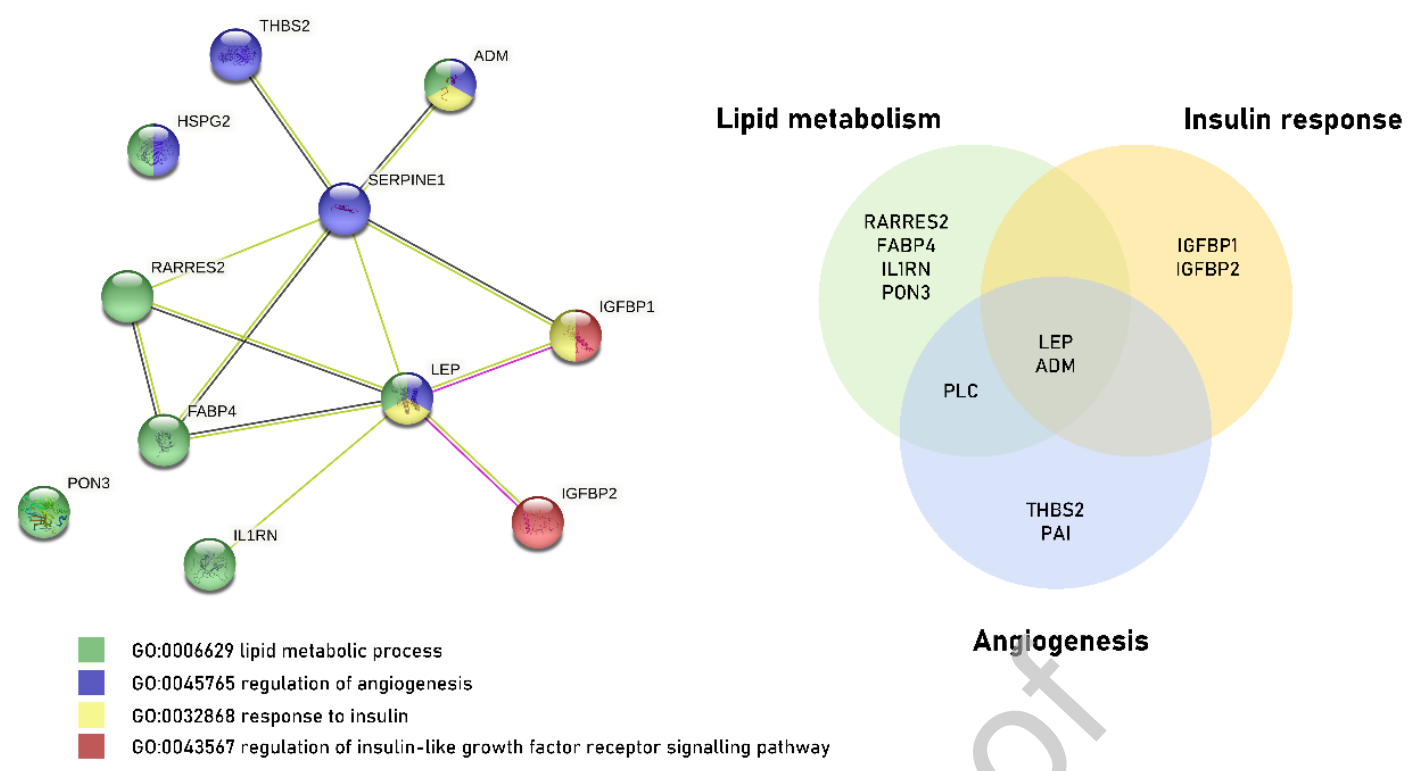

FIGURE 1. Network of protein biomarkers which were significantly differentially detected in patients with obesity compared to non-obese patients (FDRq $<0.05)$. The full names of the proteins are depicted in Supplemental Table 1. The Search Tool for the Retrieval of Interacting Genes/Proteins (STRING) database was used to analyse functional enrichment (GO biological processes and KEGG pathways) using these proteins. Four major pathways could be retrieved from this analysis as reflected by corresponding colours (left). Meta-clustering revealed involvement of proteins in single, or in multiple biological processes (right). P3NP was not depicted in the figure as it is a product of collagen production which could not be analysed for protein-protein interactions. Gene names are used as input for the network analysis: SERPINE1 generates the protein PAI and HSPG2 generates the protein PLC. 


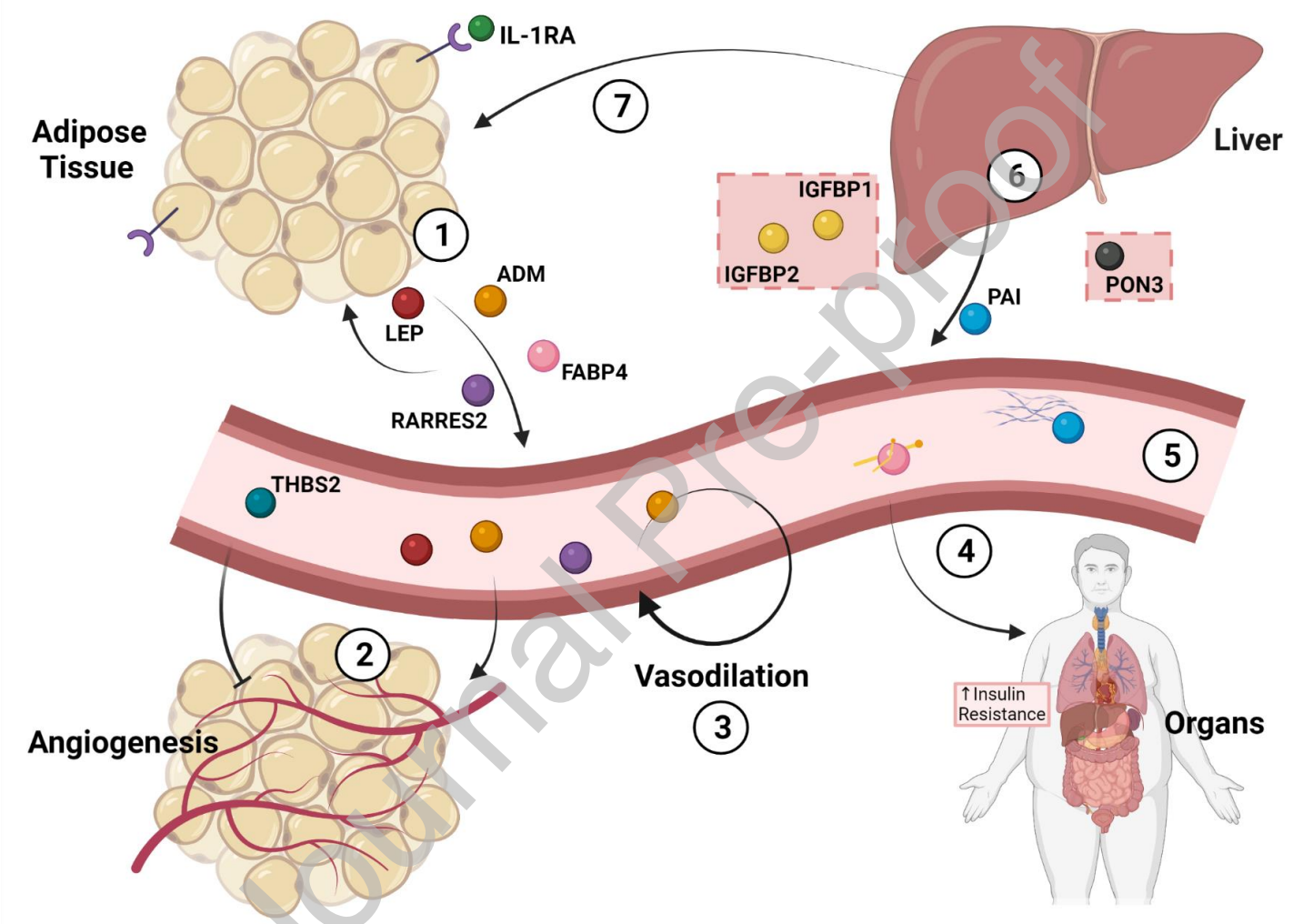


FIGURE 2. Summary of the biological processes of the biomarkers which are differentially expressed in obese patient compared to non-obese patients. (1) the adipokines leptin (LEP), adrenomedullin (ADM), fatty acid-binding protein 4 (FABP4) and chemerin (RARRES2) are secreted from the adipocytes into the circulation. Leptin and chemerin work in an autocrine feedback loop to stimulate oxidative substrate metabolism. (2) Leptin, adrenomedullin and chemerin all stimulate angiogenesis, thrombospondin-2 (THBS2) is a well-known modulator of extracellular matrix remodelling during angiogenesis. (3) Adrenomedullin causes dilation of the blood vessels by exerting its effect on the vascular smooth muscle cells. (4) Fatty acid-binding protein 4 acts as a chaperone for long-chain fatty acids (FA) in the circulation, and transports these to the organs. (5) Plasminogen activator (PAI)-1 blocks the activation of fibrinolysis, thereby limiting the dissolution of the fibrin clot. (6) Paraoxonase-3 (PON3) is anchored to high-density lipoprotein (HDL) particles in the circulation, and prevent low-density lipoprotein (LPL) particles from oxidation. (7) Insulin-like growth factor-binding protein-1 and 2 (IGFBP-1 and IGFBP-2) are strongly associated with insulin sensitivity and prevent adipocyte differentiation and adipogenesis.

The proteins in the red squares (IGFBP-1, IGFBP-2 and PON3) are decreased in obese patients. P3NP was not depicted in the figure as it is a product of collagen production which could not be analysed for protein-protein interactions. Figure created with BioRender.com 
TABLE 1. Baseline characteristics of the patients according to waist circumference

\begin{tabular}{|c|c|c|c|}
\hline Characteristics & $\begin{array}{c}\text { Normal Waist } \\
\text { Cirmcumference } \\
n=211\end{array}$ & $\begin{array}{c}\text { High Waist } \\
\text { Circumference } \\
n=299 \\
\end{array}$ & p-value \\
\hline Age (years) & $73(69-79)$ & $73(68-78)$ & 0.68 \\
\hline Male sex (\%) & $180(85)$ & $200(67)$ & $<0.001$ \\
\hline BMI $\left(\mathrm{kg} / \mathrm{m}^{2}\right)$ & $25.4(23.7-27.2)$ & $30.8(28.1-34.2)$ & $<0.001$ \\
\hline $\mathrm{WC}(\mathrm{cm})$ & $95(88-99)$ & $109(103-116)$ & - \\
\hline Heart rate (b.p.m.) & $59(54-65)$ & $62(56-69)$ & 0.002 \\
\hline Systolic blood pressure (mmHg) & $140(125-153)$ & $141(130-157)$ & 0.05 \\
\hline Diastolic blood pressure ( $\mathrm{mmHg}$ ) & $78(71-86)$ & $78(71-84)$ & 0.5 \\
\hline \multicolumn{4}{|c|}{ Medical history (\%) } \\
\hline Hypertension & $148(70)$ & $253(85)$ & $<0.001$ \\
\hline Diabetes mellitus & $55(26)$ & $153(51)$ & $<0.001$ \\
\hline Coronary artery disease & $172(82)$ & $193(65)$ & $<0.001$ \\
\hline Stroke/TIA & $7(3)$ & $20(7)$ & 0.09 \\
\hline COPD & $10(5)$ & $21(7)$ & 0.29 \\
\hline \multicolumn{4}{|c|}{ Echocardiography } \\
\hline LV ejection fraction (\%) & $62(57-66)$ & $64(59-67)$ & 0.05 \\
\hline Indexed LV mass $\left(\mathrm{g} / \mathrm{m}^{2}\right)$ & $92(80-106)$ & $97(82-114)$ & 0.017 \\
\hline LV hypertrophy & $42(21)$ & $91(35)$ & 0.001 \\
\hline Indexed LA volume $\left(\mathrm{ml} / \mathrm{m}^{2}\right)$ & $32(27-38)$ & $29(24-35)$ & 0.003 \\
\hline$E / e^{\prime}$ & $8.9(7.3-10.8)$ & $9.5(7.8-11.8)$ & 0.009 \\
\hline \multicolumn{4}{|c|}{$L a b$} \\
\hline eGFR $\left(\mathrm{ml} / \mathrm{min} / 1.73 \mathrm{~m}^{2}\right)$ & $73(63-86)$ & $72(61-84)$ & 0.15 \\
\hline Urea (mmol/L) & $8(5.5-13.6)$ & $9.3(6-14.6)$ & 0.12 \\
\hline NT-proBNP (pg/mL) & $279(179-422)$ & $219(154-398)$ & 0.03 \\
\hline Hemoglobin (g/dL) & $14.2(13.3-14.9)$ & $14(13-14.8)$ & 0.09 \\
\hline Sodium (mmol/L) & $140(138-141)$ & $139(138-141)$ & 0.18 \\
\hline Potassium (mmol/L) & $4.3(4.1-4.5)$ & $4.3(4.1-4.6)$ & 0.59 \\
\hline \multicolumn{4}{|c|}{ Medication (\%) } \\
\hline Antiplatelet & $173(82)$ & $228(76)$ & 0.12 \\
\hline Beta-blocker & $155(74)$ & $198(66)$ & 0.08 \\
\hline ACE inhibitor or ARB & $158(75)$ & $242(81)$ & 0.1 \\
\hline Thiazides & $23(11)$ & $64(21)$ & 0.002 \\
\hline Lipid-lowering agent & $176(83)$ & $243(81)$ & 0.53 \\
\hline
\end{tabular}

Values are median (interquartile range)

$A C E$, angiotensin-converting enzyme; $A R B$, angiotensin receptor type I/ blocker; BMI, body mass index; COPD, chronic obstructive pulmonary disease; GFR, glomerular filtration rate; $L A$, left atrium; $L V$, left ventricle; $P C l$, percutaneous coronary intervention; TIA, transient ischemic attack; WC, waist circumference.

High waist circumference ( $\geq 102 \mathrm{~cm}$ for men and $\geq 88 \mathrm{~cm}$ for women characterizing abdominal obesity); NWC, normal waist circumference ( $<102 \mathrm{~cm}$ for men and $<88 \mathrm{~cm}$ for women) 
TABLE 2. Proteins associated with a high waist circumference in the blood sample at baseline (before spironolactone treatment)

\begin{tabular}{|c|c|c|}
\hline Protein & & Waist Circumference \\
\hline \multicolumn{3}{|c|}{ Proteins associated with high waist circumference and high BMI* } \\
\hline Adrenomedullin & $\mathrm{adm}$ & $9.03(6.35-11.7)$ \\
\hline Thrombospondin-2 & thbs2 & $8.68(4.61-12.74)$ \\
\hline Retinoic acid receptor responder protein-2 & rarres2 & $8.61(5.51-11.71)$ \\
\hline Fatty-acid binding protein-4 & fabp4 & $7.52(6.24-8.81)$ \\
\hline Perlecan & plc & $7.51(4.09-10.92)$ \\
\hline Leptin & lep & $7.24(6.43-8.05)$ \\
\hline Interleukin receptor 1 receptor antagonist & il1ra & $6.94(5.35-8.53)$ \\
\hline Procollagen III amino terminal propeptide & p3np & $3.05(1.31-4.79)$ \\
\hline Plasminogen activator inhibitor-1 & pai & $2.71(1.73-3.7)$ \\
\hline Insulin-like growth factor-binding protein-1 & igfbp1 & $-3.65(-4.63--2.67)$ \\
\hline Insulin-like growth factor-binding protein-2 & igfbp2 & $-4.22(-5.91--2.52)$ \\
\hline Paraoxonase-3 & pon3 & $-4.35(-6.14--2.55)$ \\
\hline \multicolumn{3}{|c|}{ Proteins associated with high waist circumference but not with a high BMI } \\
\hline Hepatocyte growth factor & hgf & $4.44(2.09-6.78)$ \\
\hline Cathepsin D & ctsd & $4.21(1.95-6.46)$ \\
\hline Interleukin-18 receptor-1 & $\| 18 \mathrm{r} 1$ & $4.3(2-6.61)$ \\
\hline Cathepsin B & ctsb & $3.69(1.66-5.72)$ \\
\hline Interleukin-6 & 116 & $1.99(0.88-3.11)$ \\
\hline $\begin{array}{l}\text { Tumor necrosis factor receptor superfamily } \\
\text { member-11a }\end{array}$ & tnfrsf11a & $3.99(1.74-6.25)$ \\
\hline c-c motif chemokine ligand-16 & $\mathrm{ccl} 16$ & $2.74(1.17-4.31)$ \\
\hline Cluster of differentiation $8 a$ & cd8a & $3.12(1.39-4.85)$ \\
\hline High-sensitive troponin $\mathrm{T}$ & hstnt & $3.21(1.41-5)$ \\
\hline $\begin{array}{c}\text { Tumor necrosis factor receptor superfamily } \\
\text { member-6 }\end{array}$ & fas & $4.99(2.19-7.8)$ \\
\hline
\end{tabular}

Values are the 6 -coefficient (95\% confidence interval). All reported values were significant using a false discovery rate (FDR) of 5\%. The B-coefficients represent the changes in Log2 NPX values, as per Olink ${ }^{\circledR}$ standard reporting of protein concentrations.

* See supplemental Table 5 for the proteins associated with a high BMI $\left(\geq 30 \mathrm{~kg} / \mathrm{m}^{2}\right)$. The 12 proteins which were associated with both measures for obesity were selected for biological pathway analysis.

High waist circumference ( $\geq 102 \mathrm{~cm}$ for men and $\geq 88 \mathrm{~cm}$ for women characterizing abdominal obesity). 
TABLE 3. Association between spironolactone and primary outcomes from the HOMAGE trial depending on waist circumference

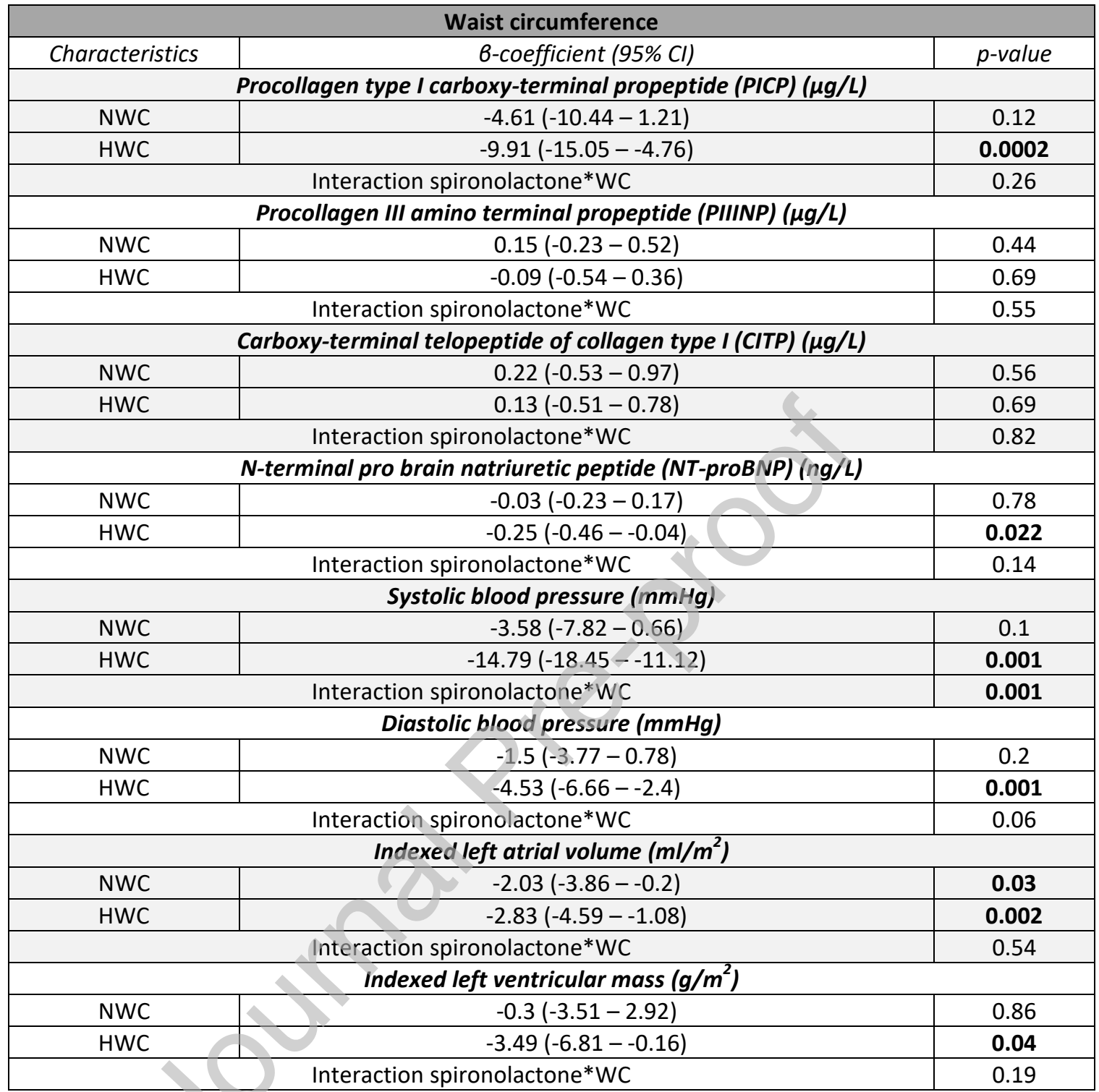

HWC, high waist circumference; NWC, normal waist circumference.

High waist circumference ( $\geq 102 \mathrm{~cm}$ for men and $\geq 88 \mathrm{~cm}$ for women characterizing abdominal obesity). 